\title{
MODERNIDAD Y POSTMODERNIDAD: REFLEXIONES DESDE AMERICA LATINA
}

Luis Armando González*

\section{Jn siglo de modernidad en América Latina}

lo largo del siglo $\chi X$, los regímenes latinoamericanos -a
través del compromiso intelectual y político de sus élites
dirigentes - han buscado por todos los medios y a cualquier costo ser modernos. Y ese "ser modernos" ha significado básicamente intentar la modemización de las estructuras socio-económicas y políticas de sus respectivas sociedades nacionales. Si traducimos el "ser modernos" por "vivir en la modernidad", en América Latina modernidad ha sido sinónimo de modernización, entendida esta última como una etapa superior de la evolución social en la que se habría impuesto la eficiencia y la racionalidad instrumental -como principio de organización de la vida social, económica y política- y se habría superado la lógica de organización de las sociedades tradicionales. La modernización sería, pues, expresión del proceso histórico en el que las sociedades latinoamericanas transitarían inexorablemente de la tradición a la modernidad.

En los umbrales del siglo XXI, la modernidad soñada por gobernantes $\mathrm{e}$ intelectuales del subcontinente no ha llegado. La sociedad tradicional sigue presente en América Latina, y por mo-

\footnotetext{
* Director del CIDAI
} 
mentos irrumpe violentamente en la seguridad "moderna" de las grandes ciudades, como ocurrió en México con el levantamiento en los Altos de Chiapas, en enero de 1994. Hacia fines de siglo, la modernidad que las élites intelectuales y políticas latinoamericanas creían ya alcanzada se ha desvanecido. De México a la Argentina, los sucesivos esfuerzos modernizadores ni han terminado con el retraso socio-económico de la región ni han acercado a las sociedades latinoamericanas a las sociedades desarrolladas de Europa occidental y Estados Unidos. Pese a ello, la modemidad sigue siendo -ahora más que nunca- la gran aspiración de las élites latinoamericanas; un siglo de frustaciones no ha sido suficiente para desalentar a las élites de la región respecto de la bondades que la modernidad ha de traer consigo.

Sin embargo, son pocos los epígonos de la modernidad que han reflexionado seriamente sobre el significado de la misma. Los modemizadores de principios y de mediados del siglo - los gestores de la industrialización y la integración regional- asumieron que sabían lo que era la modernidad, y se lanzaron a implementar medidas que llevarian a su definitiva consecución. Los modernizadores del fines de siglo parten del mismo supuesto: ellos saben qué es la modernidad y saben cuáles son los requisitos sociales. económicos y políticos para implantarla. Y, precisamente, es este presunto saber el que les ha impedido caer en la cuenta de que la modernidad - más que un problema resuelto- involucra un manojo de problemas por resolver.

Parte de la solución de estos problemas - o por lo menos de un correcto planteamiento de los mismos - comienza con la dilucidación de los conceptos involucrados en la discusión en torno a la modernidad. Hay que repensar nuevamente no sólo si modernización es sinónimo de modernidad, sino qué se entiende strictu sensu por esta última. Adicionalmente, la pregunta por la modernidad se complica porque si en América Latina el sueño es la modemidad, las sociedades europeas - al menos así lo creen y lo viven muchos de sus miembros - han dejado hace tiempo la modernidad y han arribado a la postmodernidad. Nos parece que una tarea fundamental que se impone en este repensar la modernidad es la clarificación no sólo de la noción misma de modernidad, sino de la noción de postmodernidad, sin la cual la primera no se esclarecería suficientemente. 
¿Qué es la modernidad? ¿Qué es la postmodernidad? ¿El post significa una superación de la modemidad o significa una radicalización de la misma? Respondidas estas preguntas, habría que avanzar hacia la formulación de otras como las siguientes: ¿son o no son modernas la sociedades latinoamericanas? Si se responde afirmativamente, ¿en qué consiste la modernidad latinoamericana? ¿Implica la misma la superación de la tradición, o acaso la especifica modernidad de nuestras sociedades la supone? ¿Qué significa la postmodernidad europea para la modernidad latinoamericana? ¿Es un camino a seguir o acaso América Latina está viviendo ya su propia postmodernidad?

\section{Modernidad: acepciones básicas del concepto}

T a noción de modernidal posee al menos tres acepciones básiLas: un sentido histórico-social, un sentido cultural y un sentido filosófico.

a) En el primer sentido, la idea de modernidad nos remite a la fase histórica dominada por el capitalismo clásico, desde los siglos XIV y XV hasta mediados del siglo XX, que es para algunos autores el momento de transición del capitalismo liberal -el capitalismo 'e la libre competencia- al capitalismo de intervencionismo estatal en la economía y en la política, esto es, el "capitalismo de regulación estatal" (Habermas, Offe). Como fase histórico-social, la modernidad estaría caracterizada por el nacimiento y consolidación de la burguesía como clase dominante, así como por la afirmación de los tres ideales con los que la burguesía legitimaría su dominación: el individualismo, el racionalismo y el utilitarismo. En el marco de estos ideales -que son los ideales de la modernidad- la burguesía configuraría lo que Habermas llama la "racionalidad instrumental", consistente en una racionalidad cuyo fin último es el dominio instrumental sobre la realidad natural: una racionalidad orientada hacia la manipulación técnica de la naturaleza.

b) En su acepción cultural, el término "modernidad" hace referencia a la dinámica cultural que se inicia en occidente con el renacimiento - siglo XIV-y que, transitando por las corrientes naturalistas — segunda mitad del siglo XDX-, culmina en el realismo y el surraealismo - a partir de la segunda mitad del siglo XIX hasta mediados del siglo XX-. A nivel cultural, la modernidad se iden- 
tifica con los movimientos de vanguardia, particularmente con la llamada "modernidad estética", que, como señala Habermas, "asumió contornos claros en la obra de Baudelaire" y luego "se desplegó en varios movimientos de vanguardia y finalmente alcanzó su apogeo en el café Voltaire de los dadaístas y en el surrealismo"1.

La "modernidad estética" hizo de la modernidad un "clima cultural", marcado por "la conciencia del tiempo nuevo" (Bergson), que se expresa "mediante metáforas de vanguardia, la cual se considera como invasora de un territorio desconocido... y conquistando un futuro todavía no ocupado. La vanguardia debe encontrar una dirección en un paisaje por el que nadie parece haberse aventurado todavía" 2 . El horizonte de esa búsqueda es el futuro como "territorio desconocido" con la confianza que en el mismo se oculta el secreto de la felicidad humana; la seguridad de ocuparlo la ofrece la razón, que no conoce ostáculos en el camino que conduce a la humanidad hacia su felicidad plena. Es por ello que José María Mardones puede decir que la cultura moderna está edificada sobre un paradigma de racionalidad y humanismo, que ha sido asimilado en buena medida del modelo de civilización propio del mundo helénico antiguo3.

c) En su sentido sentido filosófico, el término "modernidad" hace referencia a la tradición filosófica que centra su atención en la subjetividad humana, con el propósito de comprender más cabalmente lo que es la realidad. En este sentido, decir "filosofía de la modernidad" es equivalente a decir "filosofía de la subjetividad"; y este modo de hacer filosofía se contrapondría a las elaboraciones filosóficas propias de la antigüedad helénica, que se caracterizarían por centrar su atención no en el yo subjetivo, sino en la objetividad del mundo natural. Si el horizonte filosófico de la antigüedad helénica es el horizonte de la objetividad, el horizonte filosófico de la modernidad es el horizonte de la subjetividad.

Como horizonte filosófico, la filosofía de la subjetividad se inicia con Orígenes (185-254) y san Agustín (354-430), se continúa con Descartes (1596-1650), Kant (1724-1804) y los idealistas alemanes -Fichte y Schelling-, y alcanza su máxima expresión en Hegel (1770-1831). En ellos, el pensamiento filosófico de desplaza de la 
naturaleza al hombre, entendido como conciencia subjetiva y autónoma, es decir, como un Yo que en cuanto tal es razón pura (ratio) y yo pensante (ego cogitans). El idealismo de la filosofía moderna hunde sus raíces justamente en esta absolutización de la subjetividad, que en Hegel termina -al convertirse en Idea Absoluta- por subsumir la totalidad de la realidad.

La subjetividad lo es todo para la filosofía moderna. Pero lo es en tanto subjetividad racional. Y es que la razón no sólo ofrece al hombre las certezas más absolutas, sino que es la garantía última de que la felicidad es una meta segura en la evolución humana. Como enseñó Kant, la razón es la facultad que permite al hombre emanciparse de las ataduras misticas y religiosas, que le esclavizan y le impiden alcanzar su mayoría de edad. Como enseñó Marx, yendo más lejos que Kant, la razón no sólo posibilita la emancipación de las conciencias, sino la emancipación de la miseria. Ambos autores expresaron los ideales más profundos de la Ilustración: la confianza en la capacidad de la razón para emancipar a la humanidad, encaminándola por los senderos del progreso, la libertad, la igualdad y la fraternidad.

Las certezas y seguridades proclamadas por la filosofía moderna tuvieron un influjo decisivo en la configuración del "clima cultural" de la modernidad, que a su vez no fue ajeno a las necesidades de legitimación de la burguesía. El conjunto de estos aspectos -entretegidos en una compleja red de complementariedades y contradicciones- dieron a las sociedades del capitalismo liberal un perfil socio-cultural específico. Este perfil se ha desvanecido con el fin del capitalismo liberal y el advenimiento del capitalismo postindustrial hacia mediados del siglo $\mathrm{XX}$. Las seguridades y certezas de la modernidad se han esfumado: en fin, todo lo sólido en que se asentaba la modernidad se desvanece el aire (M. Berman). Este "desvanecimiento" no indica sino que la modernidad se está autotrascendiendo, es decir, que está transitando hacia la postmodernidad.

\section{Postmodernidad: acepciones básicas del concepto}

A 1 igual que la noción de modernidad, la idea de postmo1 demidad posee cuando menos tres sentidos básicos: un sentido histórico social, un sentido cultural y un sentido filosófico. 
a) En su acepción histórico-social, la idea de postmodernidad hace referencia a lo que se ha dado en llamar "sociedad postindustrial" (Bell), "neocapitalismo" (Mandel) o "capitalismo tardío" (Habermas). De este modo, las sociedades postmodernas serían aquellas en las que habría llegado a su fin el capitalismo de la libre competencia - las sociedades de capitalismo avanzado- y se habría implantado un capitalismo de regulación estatal4. La fase histórica postmoderna, que se inicia para muchos desde mediados del siglo $X X$, se caracterizaría no sólo por la gran concentración monopólica de capital y por el ejercicio del poder económico, social y político por parte de élites tecnocráticas y burocráticas, sino por la transformación del conocimiento científico en una fuerza productiva fundamental.

El concepto de sociedad postindustrial pretende subrayar esta centralidad del conocimiento teórico - léase científico-técnicocomo eje en tomo al cual estaría articulada la nueva organización de la sociedad, la nueva tecnología y el crecimiento económico. "Por esta razón -dice D. Bell-, la naturaleza y los tipos de apoyo estatal a la ciencia, la politización de la ciencia y los problemas sociológicos de organización del trabajo por equipos de científicos, se han convertido en cuestiones políticas centrales en la sociedad postindustrial"5. El predominio de la científico-técnico explicaría, así, la centralización extrema -en manos de los tecnócratas- del poder de decisión social, económica y política.

b) En su sentido cultural, la noción de postmodernidad expresa ante todo un "clima cultural"caracterizado por una actitud de rechazo y de crítica a los valores socio-culturales y políticos de la sociedad burguesa liberal, edificada sobre el paradigma de la "razón instrumental" y el "individualismo posesivo". El clima cultural postmoderno es un clima contracultural: no acepta los valores de la modernidad, es decir, las certezas y seguridades propias de la Ilustración; eso sí, acepta sin reparos el "desvanecimiento" de dichas certezas y seguridades.

En una palabra, la postmodemidad cultural se afinca en la crítica del optimismo y la confianza en la razón ilustrada propios de la cultura moderna. Ello hace de la misma no sólo una cultura marcada por pesimismo radical acerca de los logros y las metas de la sociedad moderna, sino un cultura postilustrada, que pretende afir- 
marse a partir de la superación de la Ilustración. Esta superación tiene como ejes de referencia los siguientes aspectos: a) el malestar ante la utopía del progreso de la modernidad, centrada en la racionalidad instrumental y el desarrolo económico; b) el rechazo de las propuestas críticas y emancipadoras, presas de una racionalidad totalizante y disciplinadora que no puede sino conducir a nuevas formas de opresión y esclavitud; c) la búsqueda de fórmulas que permitan la superación del racionalismo funcionalista en la estética; y d) la aceptación sin reparos no sólo de la experiencia de vivir en un mundo atravesado por un flujo enorme de informaciones, a una velocidad imposible de digerir y de dar sentido, sino de que ese mundo es un mundo plural y abierto, carente de puntos de referencia fijos y seguridades definitivas, donde reina el relativismo de las visiones de mundo y donde los únicos consensos posibles son los consensos locales.

c) En su sentido filosófico, la idea de postmodernidad hace referencia a un modo de plantearse los problemas filosóficos fundamentales distinto a como lo hace la filosofía moderna y a como lo hace la filosofía clásica griega. La filosofía postmoderna ha encontrado a sus cultivadores más importantes entre los posestructuralistas frances (Lyotard, Braudillard, Foucault), quienes han formulado duras críticas a cualquier tentativa de hacer filosofía en el sentido clásico, es decir, en el sentido de metafísica. En deuda con Nietzche, los filosófos postmodemos sostienen que el hombre carece en el mundo actual de un asidero seguro; $y$, sin poder aferrarse a verdades indubitables, vaga inciertamente en un mundo cuya característica fundamental es la "fragmentación". Precisamente esta es la constatación de los filosófos postmodernos- ese es el rasgo distintivo de las sociedades occidentales avanzadas, saturadas de información y una enorme variedad de puntos de vista: la inexistencia de verdades seguras y absolutas. $Y$ si ello es así, la metafísica -como búsqueda de verdades y principios últimosya no tiene razón de ser. Hay que explorar los caminos del fragmento: hay que volverse hacia el relativismo de los juegos del lenguaje y la sensibilidad estética. Hay que optar por la paralogía, rechazando la razón totalizante y fundamentadora6.

En definitiva, el quehacer filosófico postmoderno abandona los supuestos de la metafísica occidental - la pregunta por la unidad 
última de la realidad y la confianza en la razón para acceder conceptualmente a la verdad de esa unidad-. Y lo hace porque, en opinión de sus cultivadores, ni la realidad posee una unidad sino que es más bien una realidad fragmentada-, ni la razón humana es tan omnipotente - sino que está más bien dominada por la irracionalidad-, ni la verdad es algo a alcanzar de una vez y por siempre $\rightarrow$ sino que es algo provisional y relativo a comunidades lingüísticas particulares-. Hacer filosofía en la postmodernidad significa criticar y rechazar los supuestos de la metafísica y aceptar sin reparos la fragmentación de la realidad, la incapacidad de la razón para acceder a la dinámica de la misma y la existencia de una pluralidad de verdades, siempre evanescentes, provisionales $\mathrm{y}$ relativas.

\section{4. ¿Qué significa el "post"de la modernidad?}

T a postmodernidad, como hemos visto, supone una superación Lde la modernidad. Supone no sólo una crítica de los valores de la modermidad, sino la fundación de nuevos valores. Sin embargo, estos nuevos valores tienen su origen en la propia modernidad: es ésta la que ha desplegado no sólo una razón sustentada en la irracionalidad, sino una razón cuyo potencial crítico se ha volcado hacia sí misma. En este sentido, la postmodernidad hunde sus raíces en la modernidad; es la modernidad misma autocuestionàndose y autosuperándose. La postmodernidad, pues, no es más que la radicalización de las tendencias autocríticas de la modernidad.

El "post" de la modernidad no señala un más allá de la modernidad, sino un sumergirse en la modernidad, pero desde "la paradoja del futuro" (Lyotard). El "post" de la modernidad apunta a un momento de unmaking (deshacimiento) (I. Hassan) en la mente occidental de las certezas y seguridades modernas. Ser postmoderno es -como dice Lyotard- "comprender según la paradoja del futuro (post) anterior (modo)". Y aceptar que la modernidad está viviendo un "momento postmoderno" (Wellmer) no sólo supone aceptar con Marshall Berman que "todo lo sólido se desvanece en el aire", sino que ese desvanecimiento tiene que ser llevado hasta sus últimas consecuencias, haciendo "resistencia" a los que todavía apuestan por el proyecto Dustrado. Asumir la postmodernidad, 
pues, significa asumir la experiencia de fragmentación del mundo moderno y comprometer las propias energías en la radicalización de la misma, sin "nostalgias" y renunciando "sin desencanto a los metadiscursos legitimadores que es la característica fundamental que separa el saber moderno del postmoderno"7.

\section{5. ¿Cómo repensar la modernidad-postmodernidad en América Latina?}

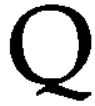

ué duda cabe que América Latina ha tenido su propia modernidad, de la cual la modernización ha sido nada más un aspecto. No se ha tratado de una modernidad idéntica de la seguida por las sociedades europeas o por Estados Unidos, pero sí de una modernidad que no ha sido ajena a los valores culturales y al proyecto económico-social de la modernidad alcanzada por estas sociedades.

Las élites intelectuales y políticas de la región creyeron siempre que la modemidad latinoamericana tenía que ser semejante -y seguir los pasos de- la modernidad europea (y norteamericana). No cayeron en la cuenta que la particular inserción de América Latina en occidente hizo que la región viviera su específica modernidad, no caracterizada por la superación de la tradición, sino por la persistencia de la misma y su convivencia con estilos de vida, modelos culturales y formas de organización económica altamente racionalizados y tecnificados. Tradición y modernización han marcado el perfil propio de la modernidad latinoamericana. La persistencia de la primera no sólo a impedido el arribo a una modernidad europea, sino que ha generado en las élites intelectuales y políticas la sensación de que América Latina todavía no ha llegado a la modernidad. Por su parte, la modernización se ha seguido viendo como el instrumento portador de las innovaciones necesarias para terminar de una vez por todas con la tradición.

El juego perpetuo entre ambas - persistencia de la tradición e innovaciones modernizadoras - ha dado lugar, mientras tanto, a la modernidad latinoamericana, constituida de un híbrido en el que conviven lo culto con lo popular, las melodías folklóricas con el jazz y la música clásica8, un capitalismo urbano altamente tecnificado con la expansión de corrientes nacionalistas9. Y esta modernidad latinoamericana, aún y siendo fallida si se la ve con 
los ojos de la modernidad europea, no puede ser comprendida a cabalidad si no se lee como una realidad postmoderna, sobre todo si se concibe la postmodernidad "no como una discontinuidad o una ruptura respecto de lo moderno, sino como una reorganización de sus relaciones internas y su conexión con las tradiciones. Más que un nuevo paradigma, el postmodernismo es un tipo peculiar de trabajo sobre las ruinas de la modernidad, saqueando su léxico, agregándole ingredientes premodernos y modernos" 10 .

En definitiva, como señala Canclini, la situación de América Latina hacia finales de siglo es de una situación postmoderna, en el sentido que "vivimos en la época de las tradiciones que no se fueron, la modernidad que no acaba de llegar y el cuestionamiento postmoderno de los proyectos evolucionistas que hegemonizaron este siglo"11. A esto se ha aunado el fracaso de los proyectos emancipadores de la izquierda que ha terminado por sumergir a las sociedades latinoamericanas en un pesimismo acerca del futuro y anclarlas en la inmediatez de un presente cada vez más opaco y desesperanzado.

*******

Determinar los perfiles particulares de la modernidad-postmodernidad de las diversas sociedades nacionales que integran América Latina es una tarea pendiente. Aquí sólo hemos planteado los elementos que consideramos necesarios para dar inicio a la discusión, pensando sobre todo en propiciar un acercamiento crítico a la modernidad-postmodernidad específica de El Salvador. En la medida que ese acarcamiento se vaya produciendo y en la medida que este trabajo haya contribuido aunque sea mínimamente a ello, el esfuerzo empeñado en estas reflexiones se verá más que compensado.

\section{Notas}

1. Habermas, J., "La modernidad, un proyecto incompleto". En Habermas, J., et al. La postmodernidad. Barcelona, Kairos, 1985. p. 21

2. Ibid.

3. Cfr. Mardones, J. M., "Modernidad y post-modernidad: un debate sobre la sociedad actual". Razón y Fe (Madrid), septiembre-octubre, 1986 
4. Cfr. Habermas, J., La reconstrucción del materialismo histórico. Madrid, Taurus, 1981. pp. 275 y ss.

5. Bell, D., El advenimiento de la sociedad postindustrial. Madrid, Alianza, 1976. p. 143

6. Cfr. Mardones, J. M., Postmodernidad y cristianismo. El desafio del fragmento. Santander, Sal Terrae, 1988. p. 49

7. Mardones, J. M., Postmodernidad y..., p. 48

8. Cfr, Garća Canclini, N., “¿Modernismo sin modernización?”. Revista Mexicana de Sociología, No. 3, julio-septiembre, 1989. p. 187

9. Bartra, R., "La crisis del nacionalismo en México". Revista Mexicana de Sociologra. No. 3, julio-septiembre, 1989. p. 193

10. Garcla Canclini, N., Ioid. p. 186

11. Ibid. 